\section{Two-component fluid front tracking in fault zone and discontinuity with permeability heterogeneity}

Rudarsko-geološko-naftni zbornik

(The Mining-Geology-Petroleum Engineering Bulletin) UDC: $519.6: 532: 551.24: 556$

DOI: 10.17794/rgn.2021.3.2

\author{
Yousef Shiri'; Hossein Hassani \\ ${ }^{1}$ Shahrood University of Technology, Faculty of Mining, Petroleum and Geophysics Engineering, Shahrood, Iran, P.O. Box: 36199-95161, \\ yousefshiri@shahroodut.ac.ir \\ ${ }^{2}$ Amirkabir University of Technology (Polytechnic of Tehran), Department of Mining and Metallurgy Engineering, Tehran, \\ P.O. Box: 15916-34311, Iran, hhassani@aut.ac.ir
}

\begin{abstract}
Fluid front tracking is important in two-phase/component fluid flow in porous media with different heterogeneities, especially in the improved recovery of oil. Three different flow patterns of stable, viscous fingering, and capillary fingering exist based on the fluids' viscosity and capillary number (CA). In addition, fluid front and sweep efficiency are affected by the heterogeneity of the porous medium. In the current study, the heterogeneous porous media are: (1) normal fault zone or cross-bedding with heterogeneity in permeability, and (2) a fracture or discontinuity between two porous media consisting of two homogeneous layers with very low and high permeabilities, in which immiscible water flooding is performed for sweep efficiency and streamlines tracking purposes. By considering the experimental glass micromodel and the simulation results of discontinuity, a crack is the main fluid flow path. After the breakthrough, fluid inclines to penetrate the fine and coarse grains around the crack. Moreover, an increase in flow rate from 1 and 200 ( $\mathrm{ml} / \mathrm{h}$ ) in both the experimental and simulation models causes a reduction in the sweep efficiency from $14 \%$ to $7.3 \%$ and $15.6 \%$ to $10 \%$ by the moment of breakthrough, respectively. In the fault zone, the sweep efficiency and the streamline of the injected fluid showed a dependency on the interface incident angle, and the layers' permeability. The presented glass micromodel and Lattice Boltzmann Method were consistent with fluid dynamics, and both of them were suitable for a precise evaluation of sweep efficiency and visualization of preferential pathway of fluid flow through cross-bedding and discontinuity for enhanced oil recovery purposes.
\end{abstract}

\title{
Keywords:
}

discontinuity; fault; Lattice Boltzmann method; fluid front; streamline.

\section{Introduction}

Heterogeneity is important in all scales from several kilometres to centimetres, especially for the determination of primary oil saturation and oil distribution of sweep zone by an improved oil recovery process. An increase in heterogeneity and anisotropy depends on different conditions from transportation and sedimentation to diagenesis, lithification, tectonic activity, and dissolution (Bjoerlykke, 1989). Chasing fluid front in definite geometries and heterogeneities is important in enhanced oil recovery. In small scales, because of the lack of visualizations, the interpretation is challenging and vital for the overall evaluation of the main oil recovery mechanism. Fluid flow in fault/cross-bedding structure with permeability contrasts and also, in a crack between two layers with different permeabilities attracted the attention of several researchers (Weber, 1982; Kortekaas, 1985; Ringrose et al., 1993; Huang et al., 1995; Silva

Corresponding author: Yousef Shiri

yousefshiri@shahroodut.ac.ir and Dawe, 2003; Dawe et al., 2011; Conn et al., 2014; Dong et al., 2017; Xiao et al., 2018).

There are several ways to examine fluid flow in complex porous media experimentally and numerically. Stochastic geological modelling by up-scaling reservoir properties, direct simulation such as Finite element methods, and the Lattice Boltzmann Method (LBM) are examples of numerical fluid flow simulators. There are several LBM methods. For simplicity, popularity, and easy boundary conditions implantation, we use the pseudo-potential model two-component single-phase LBM. The theory of this model was introduced by Shan and Chen (Shan and Chen, 1993). In immiscible water/oil displacement, non-wetting fluid injection is the drainage process, and wetting fluid injection is the imbibition process. Both geological structure and physics of fluids are important for creating a production profile. Various experimental, and numerical simulations had investigated the effect of gravity, viscosity, capillary pressure, and flow rate within different geological structures, thicknesses, permeability and wettability on fluid flow (Dong et al., 2011; Zhang et al., 2011; Liu et al., 2015). Dawe 
et al. had a sequential study on wettability and permeability heterogeneity in some structures in pore-scale as follows: in 1990, the effects of permeability contrast, lens size, viscosity ratio, and lens heterogeneity on fluid flow were numerically considered and the results were experimentally compared with a glass-bead pack (McKean and Dawe, 1990). In 1992 and 1993, miscible and immiscible fluid displacement was experimentally performed on a lens and cross-bedding structure by a glassbead pack. In this study, layer thickness, cross-bedding angle, permeability heterogeneity, mobility ratio, and flow rate were analysed. The results showed that fluid front only depends on the homogeneity of the porous medium, capillary pressure, and fluid saturation (Dawe et al., 1992; Roti and Dawe, 1993). In 1996, the effects of wettability and permeability heterogeneity on the fluid front in cross-bedding, which depicts the sedimentary structure in the fluvial deposits or the fault zones, were investigated (Caruana and Dawe, 1996). In 2010 and 2011, the vertical layers' effects in fluid flow direction with permeability contrast were studied in pore-scale by an etched glass model (Dawe et al., 2010, 2011). Chaudhari et al., in immiscible oil/water displacement in three parallel layers with different permeabilities, showed that during the drainage process, the oil prefers to enter the pores with greater permeability. Also, during the imbibition process, the water prefers to enter the pores with a lower permeability because of the wettability and capillary pressure effects (Chaudhari et al., 2011).

Due to heterogeneity in all scales, chasing fluid front in definite geometries and heterogeneities is important. In large scales, clear interpretations show that heterogeneity affects the displacement process, but in small scales, because of the lack of visualizations, the interpretation is challenging. Several studies had visualized the oil/water displacement on a large scale, especially to show water coning (Safari et al., 2018, 2019; Safari and Ameri, 2019, 2019), but limited studies are done on a centimetre scale. Recently, Shabro, Blunt, Piller, Andrew, Menke, and Muljadi et al. performed good experimental and numerical studies on evaluating two-phase flow by X-Ray imaging (Shabro et al., 2010; Blunt et al., 2013; Andrew et al., 2014, 2015; Menke et al., 2014; Piller et al., 2014; Muljadi et al., 2016). These experimental studies demonstrate the importance of studying two-phase flows adequately, but they were costly, and using a glass micromodel and glass-bead pack are more favourable for their accuracy in small scales and cost-efficiency.

A fault/cross-bedding structure with permeability contrasts and also, in a crack between two layers with different permeabilities or a discontinuity between two different layers. These heterogeneous systems geologically exist on both small and large scales. The aim of this research is a precise evaluation of the preferential pathway of fluid flow by imbibition process (water flooding) in these structures. It enables us to visualize and investigate the effects of cross-bedding and discontinuity on fluid pathways and sweep efficiency for enhanced oil recovery purposes.

\section{Glass micromodel fabrication}

A micromodel for the evaluation of the fluid front in multiphase flow has been a beneficial tool in fluid mechanics. The main purposes of using a micromodel is the construction of any geometrical and structural patterns, direct observation of the fluid behaviour, and comparing the results with numerical simulations. There are several methods for the fabrication of a micromodel, including an etched glass micromodel (Homsy, 1987; Mohammadi et al., 2013), a sand-blasted glass micromodel (Ferer et al., 2004), an etching resin micromodel (Zerai et al., 2005; Crandall et al., 2008), and so forth.

Using a glass micromodel is the most common method for improved oil recovery. The current method, presented by Mohammadi et al., is preferable because of cost savings, fabrication safety, and the preservation of pore morphology and heterogeneity of the porous medium in comparison with other conventional methods (Mohammadi et al., 2013). In this study, a laser with $100 \mu \mathrm{m}$ engraving resolution was used for etching the pore spaces on silicon glass. Porous media were designed using Corel-Draw software. The glass used is a common flute-type flat glass with high-temperature resistance and with $4 \mathrm{~mm}$ thickness. After cleaning, washing, and drying the engraved surface with a metal brush and water, the second flat piece of the glass was put on the etched glass to cover the engraved surface. At the inlet and outlet of the model, a penetration hole was drilled to allow the fluid to pass through the etched porous medium. Then, the injection needles were placed in these holes and were temporarily fixed with glue. The bonding process of two glasses is known as "fusing". It is accompanied by a gradual temperature increase inside the oven to the melting point temperature of the glass. So, the oven temperature was increased to $460^{\circ} \mathrm{C}$ with an incremental gradient of $5^{\circ} \mathrm{C}$. Then the temperature was increased to $670^{\circ} \mathrm{C}$ with an incremental gradient of $1^{\circ} \mathrm{C}$. After that, the oven was switched off, and the micromodel was gradually cooled in the oven for one day. Then, the needles were permanently fixed by glue, and accordingly, the model was ready to setup the experiment as shown in Figure 1. A syringe pump with $10 \mathrm{ml}$ syringe, and $\mathrm{K}$ connector was used for injecting the fluid into the model. Injection speed was calculated at the inlet of the glass micromodel according to the cross-sectional area of the syringe.

\section{Lattice Boltzmann Method}

LBM can be obtained both by discretizing the Boltzmann equation, and Lattice Gas Automata (He and Luo, 1997). LBM has the capability to simulate the fluid flow in both small and large scales (Nabovati, 2009). It is more favourable due to studying viscous fingering on a 


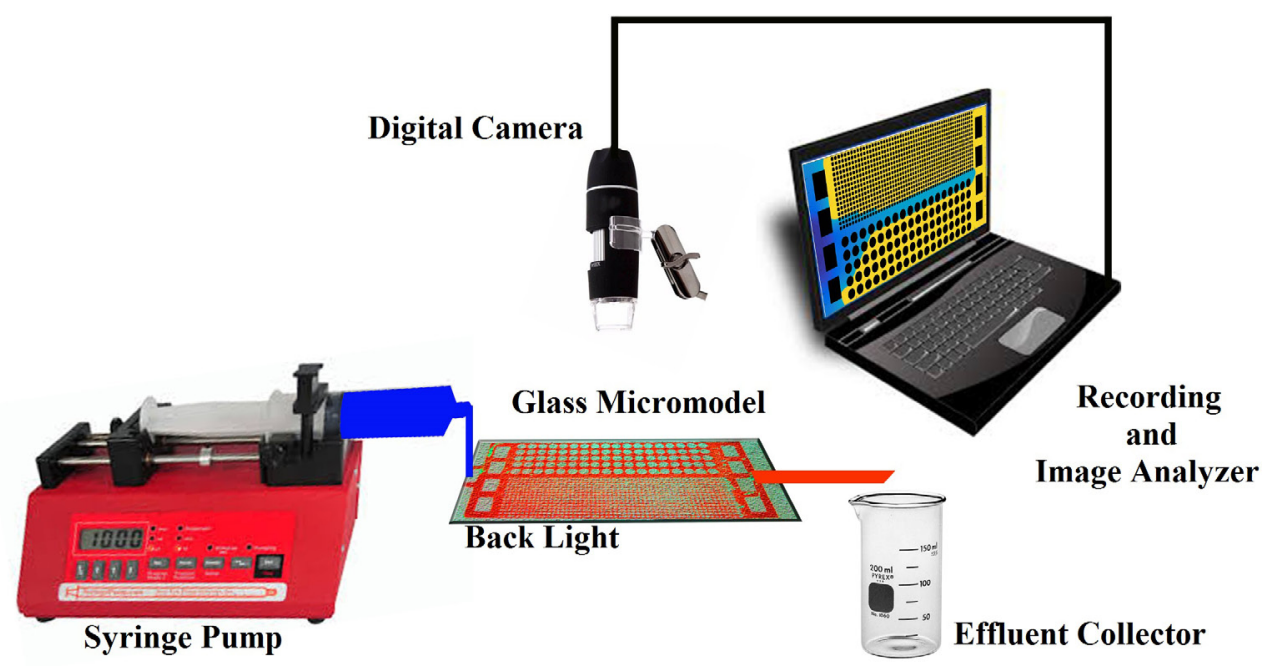

Figure 1: Experimental glass micromodel set up of fluid flow

small scale, reducing computational time, performing parallel computations, and tracking fluid front continuously (Chen and Doolen, 1998). Mean-field, free energy, colour gradient (Rothman-Keller), and pseudo-potential (Shan-Chen) are different models of LBM that are extended for two-phase/component fluid flow simulation (Gunstensen et al., 1991; Shan and Chen, 1993; He et al., 1998; Gonnella et al., 2007). In the current study, a pseudo-potential (Shan-Chen) model was used for its simplicity, computational time efficiency, and parallelism. In this method, density, viscosity, and surface tension are not independent variables (Sbragaglia et al., 2007). The Shan-Chen model is according to the intermolecular interactions of all fluids, in which the total force is equal to the summation of fluid-fluid intermolecular force, external force (like gravity), and fluid-solid adhesion force (Huang et al., 2015).

$$
\begin{gathered}
F^{\sigma}=F_{\text {int }}^{\sigma}+F^{\sigma}{ }_{\text {ext }}+F^{\sigma}{ }_{a d s} \\
F_{\text {int }}^{\sigma}(x)=-G_{\sigma \bar{\sigma}} \psi_{\sigma}(x) \sum_{x^{\prime}} \sum_{\bar{\sigma}=1}^{S} w_{i} \psi_{\bar{\sigma}}\left(x^{\prime}\right) c_{i} \\
F_{a d s}^{\sigma}(x)=-\rho_{\sigma}(x) \sum_{i} w_{i} G_{a d s}^{\sigma} S\left(x^{\prime}+c_{i}\right) c_{i} \\
F_{\text {gravity }}^{\sigma}(x)=\rho_{\sigma} g
\end{gathered}
$$

where:

$\sigma$ and $\bar{\sigma}$ - the symbols of two separate phases,

$F^{\sigma} \quad-$ total force on $\sigma$ fluid $\left(\mathrm{gr} . \mathrm{lu} / \mathrm{ts}^{2}\right)$,

$F^{\sigma}{ }_{i n t} \quad$ - fluid-fluid intermolecular force on $\sigma$ fluid (gr. $\left.\mathrm{lu} / \mathrm{ts}^{2}\right)$,

$F^{\sigma}{ }_{e x t} \quad-$ external force on $\sigma$ fluid $\left(\mathrm{gr} . \mathrm{lu} / \mathrm{ts}^{2}\right)$,

$F_{a d s}^{\sigma} \quad$ - fluid-solid adhesion force on $\sigma$ fluid $\left(\mathrm{gr} . \mathrm{lu} / \mathrm{ts}^{2}\right)$,

$G_{\sigma \bar{\sigma}} \quad-$ the fluid-fluid particle interaction or cohesion parameter,

$G_{a d s}^{\sigma} \quad-$ the fluid-solid interaction parameter,
$G^{\sigma}$ ads depends on the wettability. It is repulsive (nonwet) with a positive value or is attractive (wet) with a negative value. Shan and Chen introduced effective density $\left(\psi_{\sigma}(x, t)\right)$ as follows (Shan and Chen, 1993).

$$
\psi_{\sigma}(x, t)=\rho_{0}\left[1-\exp \left(-\frac{\rho(x, t)}{\rho_{0}}\right)\right]
$$

The total velocity $\left(u_{\sigma}^{e q}\right)$ and force of each phase $\left(u_{\text {total }}\right)$ are applied by:

$$
u_{\sigma}^{e q}=u_{\text {total }}+\frac{\tau_{\sigma} F_{\sigma}}{\rho_{\sigma}}, \quad u_{\text {total }}=\frac{\sum_{\sigma} \frac{1}{\tau_{\sigma}} \sum_{i} f_{i}^{\sigma} c_{i}}{\sum_{\sigma} \frac{1}{\tau_{c}} \rho_{\sigma}}
$$

These equations are used for the determination of velocity distribution functions in the equilibrium state $\left(f_{i}^{\sigma(e q)}\right)$ as follows:

$$
\begin{aligned}
& f_{i}^{\sigma(e q)}=w_{i} \rho_{\sigma}\left[1+\frac{c_{i} \cdot u_{\sigma}^{e q}}{c_{s}^{2}}+\frac{\left(c_{i} \cdot u_{\sigma}^{e q}\right)^{2}}{2 c_{s}^{4}}-\frac{u_{\sigma}^{e q} \cdot u_{\sigma}^{e q}}{2 c_{s}^{2}}\right], \\
& c_{s}=\frac{1}{\sqrt{3}}, \rho_{\sigma}=\sum_{i} f_{i}^{\sigma}, u_{\sigma}=\frac{1}{\rho_{\sigma}} \sum_{i} f_{i}^{\sigma} c_{i}
\end{aligned}
$$

where:

$c_{s} \quad$ - the velocity of sound speed in the lattice network (lu/ts),

$w_{i} \quad$ - the weights of the velocity distribution functions in the equilibrium state,

$i \quad$ node number,

$t \quad$ - time (ts),

$f_{i}^{\sigma} \quad$ - velocity components of each phase (dimensionless),

$f_{i}^{\sigma(e q)}$ - the equilibrium state of each phase (dimensionless),

$\rho^{\sigma} \quad$ - the density of each phase $\left(\mathrm{gr} / \mathrm{lu} \mathrm{u}^{3}\right)$,

$u_{\sigma} \quad$ - the velocity of each phase (lu/ts),

$\tau_{\sigma} \quad$ - the relaxation time (dimensionless). 
The procedure in two phases/components LBM is to consider a layer for each phase and in each node of the lattice, PDFs of phases are updated. After the initialization step the fluid variables are determined in a time marching process. This process will be stopped when the final criterion, such as breakthrough, is achieved.

$$
f_{i}^{\sigma}\left(x+c_{i}, t+1\right)-f_{i}^{\sigma}(x, t)=-\frac{1}{\tau_{\sigma}}\left[f_{i}^{\sigma}(x, t)-f_{i}^{\sigma(e q)}(x, t)\right]
$$

\subsection{Interfacial Tension and wettability Estimation}

In the Shan-Chen method, the interfacial tension and wettability are determined by a series of simulations. Surface tension is dependent on the cohesion value of $G_{c o h}$ and needs simulations for determination. The contact angle is dependent on the adhesion value of $G_{a d s}$.

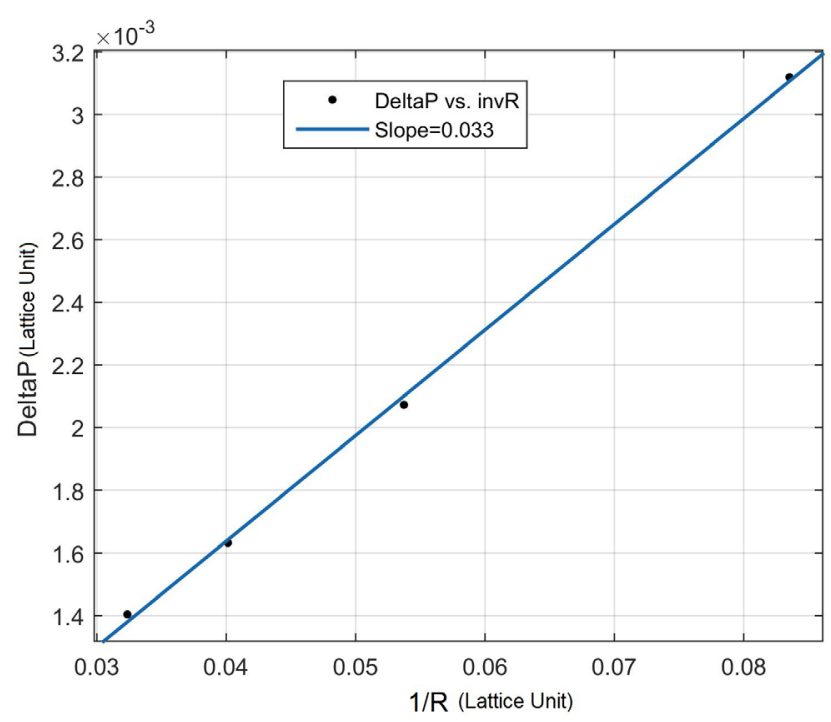

Figure 2: Interfacial tension estimation
The procedure of surface tension and contact angle determination is explained by Shiri et al. (Shiri et al., 2018). For the estimation of interfacial tension, droplets with different radii were placed in the centre of fully saturated container with another fluid. After equilibrium, the pressure inside and outside of the droplets were calculated. The slope of pressure differences versus the inverse of radii is interfacial tension. The estimated surface tension by the simulations for fluids with densities of 1 and $0.792, \tau=1$, and $G_{c o h}=3$ is 0.033 (see Figure 2). Estimations of contact angles with different adhesion parameters $\left(G_{a d s}\right)$ are shown in Figure 3. In this simulation, droplets were place on a solid surface, and after reaching equilibrium, contact angles were determined.

\subsection{Grid Size Independent Test}

The grid size independent test is done by investigating four lattice sizes. The displacing fluid (water) with a density of 1 and a relaxation time of 0.5555 is injected into porous media saturated with displaced fluid (oil) with a density of 0.875 and a relaxation time of 0.875 . The injection rate is $200(\mathrm{ml} / \mathrm{h})$. The results for lattice sizes of $400 \times 884,600 \times 1326,800 \times 1768$, and $1000 \times 2210$ are shown in Figure 4. Lattices smaller than $600 \times 1326$ had some deviations. In Figure 4(e), the interpolated lines are water saturation $\left(S_{w}\right)$ versus dimensionless time $\left(t_{D}=t /\right.$ breakthrough $)$, and no significant changes are seen in bigger sizes than $600 \times 1326$. So, lattice sizes above it do not affect the fluid flow pattern and sweep efficiency.

\section{Results and Discussion}

In immiscible fluid flows, the dominant force being applied to fluids is important. By considering the capillary number and the viscosity ratio, the flow pattern falls

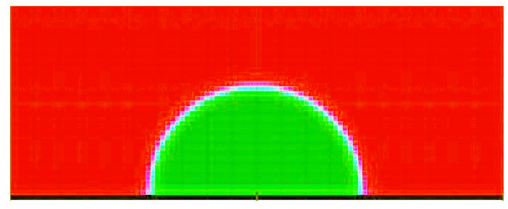

$\mathrm{G}=\mathbf{0}$

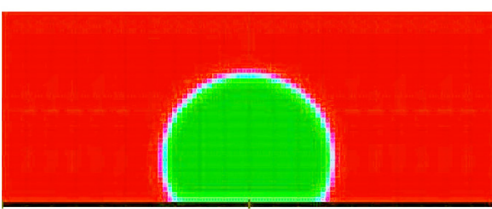

$G=0.2$

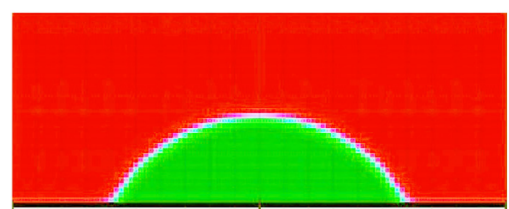

$\mathrm{G}=-\mathbf{0 . 2}$

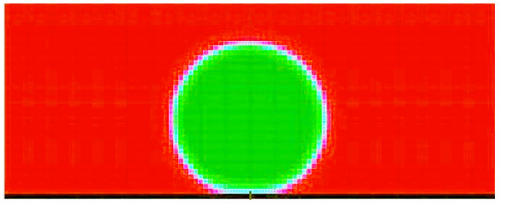

$\mathrm{G}=\mathbf{0 . 4}$

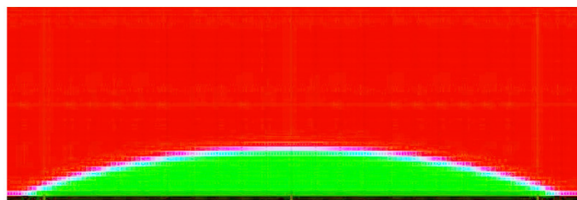

$G=-0.4$

Figure 3: Contact angle for different adhesion parameters (Gads) 

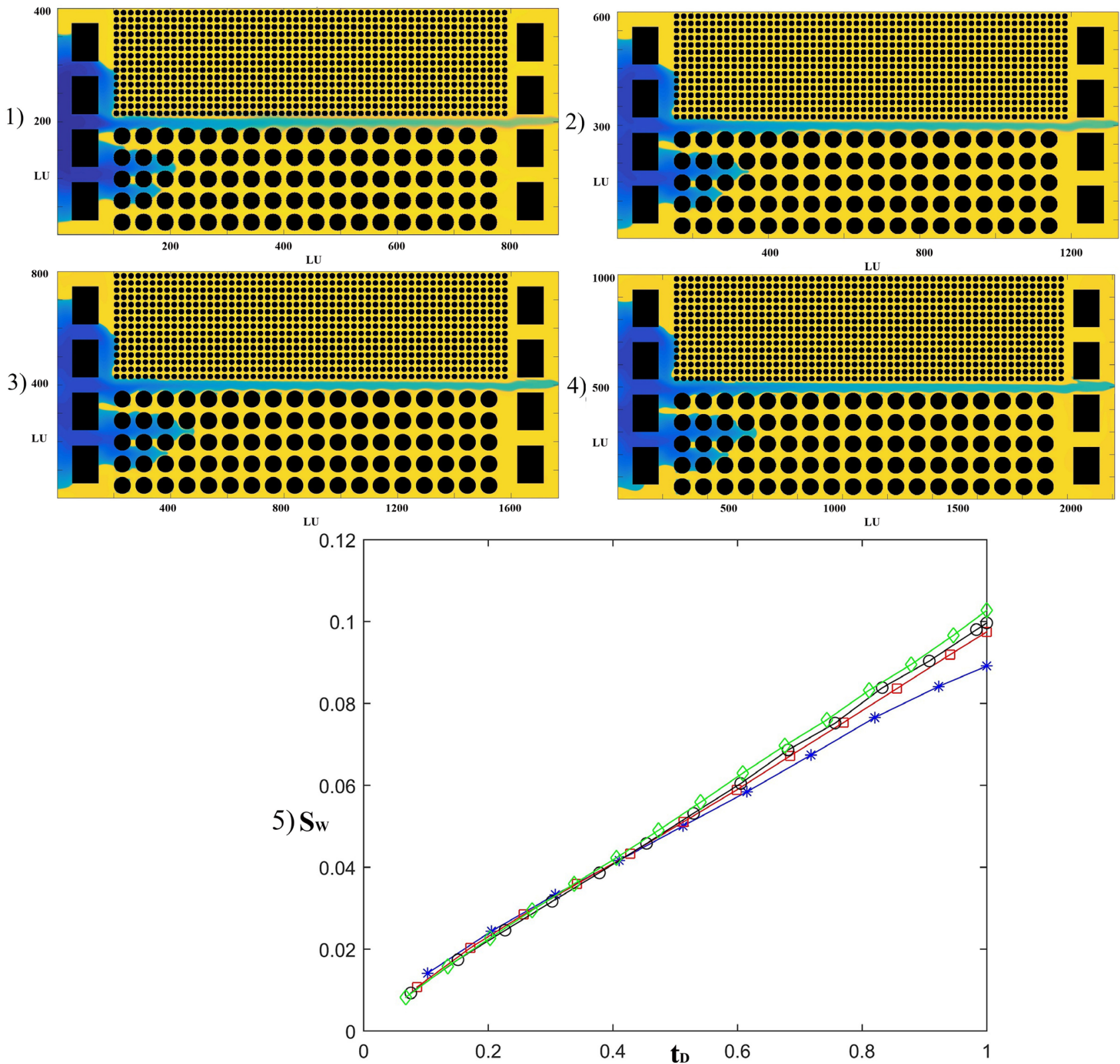

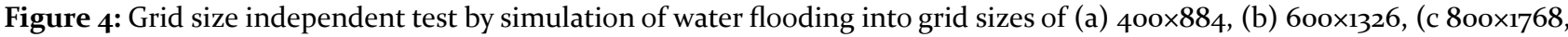
(d) $1000 \times 2210$, and (e) comparison of the sweep efficiency versus dimensionless time $\left(t_{D}\right)$ for all grid sizes as star (à): 400×884, square $\left(^{*}\right)$ : $600 \times 1326$, circle $\left({ }^{\mathrm{TM}}\right): 800 \times 1768$, and diamond $\left(^{-}\right)$: $1000 \times 2210$.

into three regions: stable movement like piston form, and two fingering regions by capillary and viscous forces (Lenormand et al., 1988; Zhang et al., 2011). In immiscible displacement with a low flow rate, the capillary force, as the main force, causes blob trapping. By increasing the injection rate, the viscous force will be dominant and consequently, this causes viscous fingering (Silva and Dawe, 2003; Holtzman, 2016). Displacing fluid viscosity over displaced fluid viscosity is known as dynamic viscosity ratio. If this ratio is smaller than one, the displacement is "unfavourable", and if it is bigger than 1, the displacement is "favourable" (Lenormand et al., 1988). Based on the range of dynamic viscosity ratio, three zones were defined. On the left-hand zone with low dynamic viscosity, the viscous force of the displaced fluid is the main force. In the middle zone or the transitional zone, the viscosity of both fluids is important. In the right-hand zone with high viscosity ratio, the displacing fluid has the dominant viscous force (Lenormand et al., 1988). In the current investigation, all simulations were in the middle zone.

\subsection{Water Flooding in Fault Structure}

Cross-beddings in the fluvial environment and faults are the most common structures. These structures are vital in petroleum reservoirs because the heterogeneity is not parallel to the flow direction (Weber, 1982; Ko- 


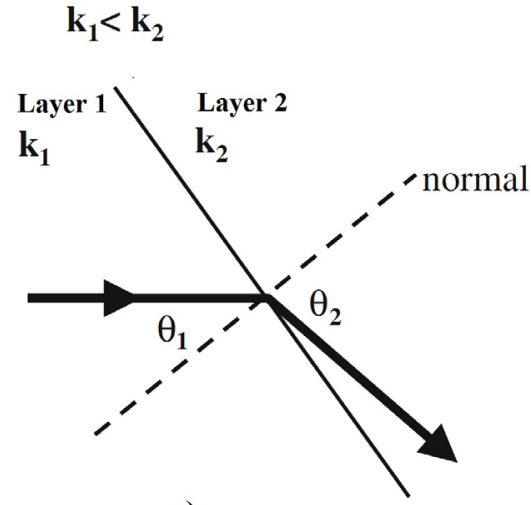

a)

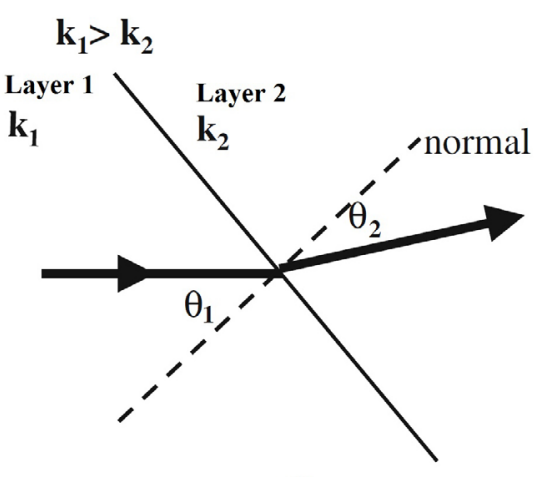

b)

Figure 5: simple Hubbert' law model

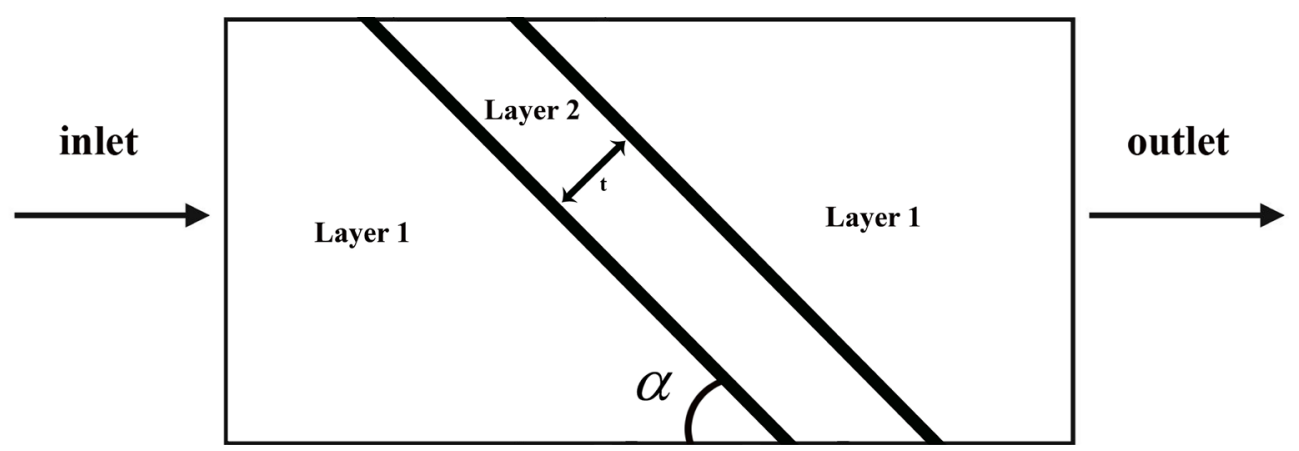

Figure 6: Cross-bedding or fault model

rtekaas, 1985; Ringrose et al., 1993; Huang et al., 1995; Silva and Dawe, 2003; Dawe et al., 2011), and it is analysed and argued here by LBM.

Before reaching the boundary, light rays and wave signals travel in straight lines in a medium. Otherwise, they obey Snell's law within the boundary. Snell's law is defined as the direct relationship of velocity and the sine of the light ray angle. In Fluid Dynamics, streamlines have similar behaviours, and the flow line is refracted when the fluid front from the first homogenous layer with the permeability of $k_{l}$ penetrates and passes through the second homogenous layer with the permeability of $\mathrm{k}_{2}$ by the following equation (Hubbert, 1940; Bear, 2013):

$$
\frac{k_{1}}{k_{2}}=\frac{\tan \theta_{1}}{\tan \theta_{2}}
$$

where:

$k_{1}$ and $k_{2}$ are the permeability of first and second layers in millidarcy, respectively,

$\theta_{1}$ is the angle of between the streamline in the first layer and normal vector of interface,

$\theta_{2}$ is the angle of between the streamline in the second layer and normal vector of interface.

If the angle of the streamlines is zero, the flow line will be normal to the boundary. If the angle of the streamlines is 90 , the flow line will be parallel to the boundary. If the angle of the streamlines is between zero and 90, the flow line will be refracted and following the Equation 8. If $k_{1}$ $>k_{2}$, the flow line will be refracted to reach normal vector of second media and if $k_{2}>k_{1}$, the flow line will be refracted to reach boundary between two media (see Figure 5) (Roti and Dawe, 1993; Bear, 2013).

As shown in Figure 6, the dimensions of the model were $2 \times 1 \mathrm{~cm}$. The interbedded layer has a 45 degree inclination, and its thickness is $15 \%$ of the model length.

In the left-hand inlet of the porous media, the Zou-He velocity boundary scheme is used (Zou and He, 1997), and open boundary condition is imposed at the righthand outlet (Mohamad, 2011). For the lower and upper boundaries and grains' surfaces, a half-way bounce-back boundary condition was used. In this section, porous media in all simulations were within a fault zone with different heterogeneities in permeability. They consist of two layers with a porosity of $40 \%$ and grain sizes of 673 $\mu \mathrm{m}(640-750 \mu \mathrm{m}$, grade 6$)$ and $425(\mu \mathrm{m})(310-425 \mu \mathrm{m}$, grade 9$)$. They correspond to the permeability ratio of 2.5 based on Berg's equation (Berg, 1970). Initial conditions and fluids and solid properties were set based on the Dawe et al. study in 2011 (Dawe et al., 2011). For wettability, the contact angle was assigned as $55^{\circ}$. The porous media were saturated with the oil with a viscosity of 1.4 centipoises ( $\mathrm{mPa} \mathrm{s}$ ) and a density of $0.792(\mathrm{~g} /$ $\left.\mathrm{cm}^{3}\right)$. Water was injected with a viscosity of $1(\mathrm{mPa} \mathrm{s})$ and a density of $1\left(\mathrm{~g} / \mathrm{cm}^{3}\right)$. The interfacial tension between two fluids was 34.1 (milli $\mathrm{N} / \mathrm{m}$ ). After changing 

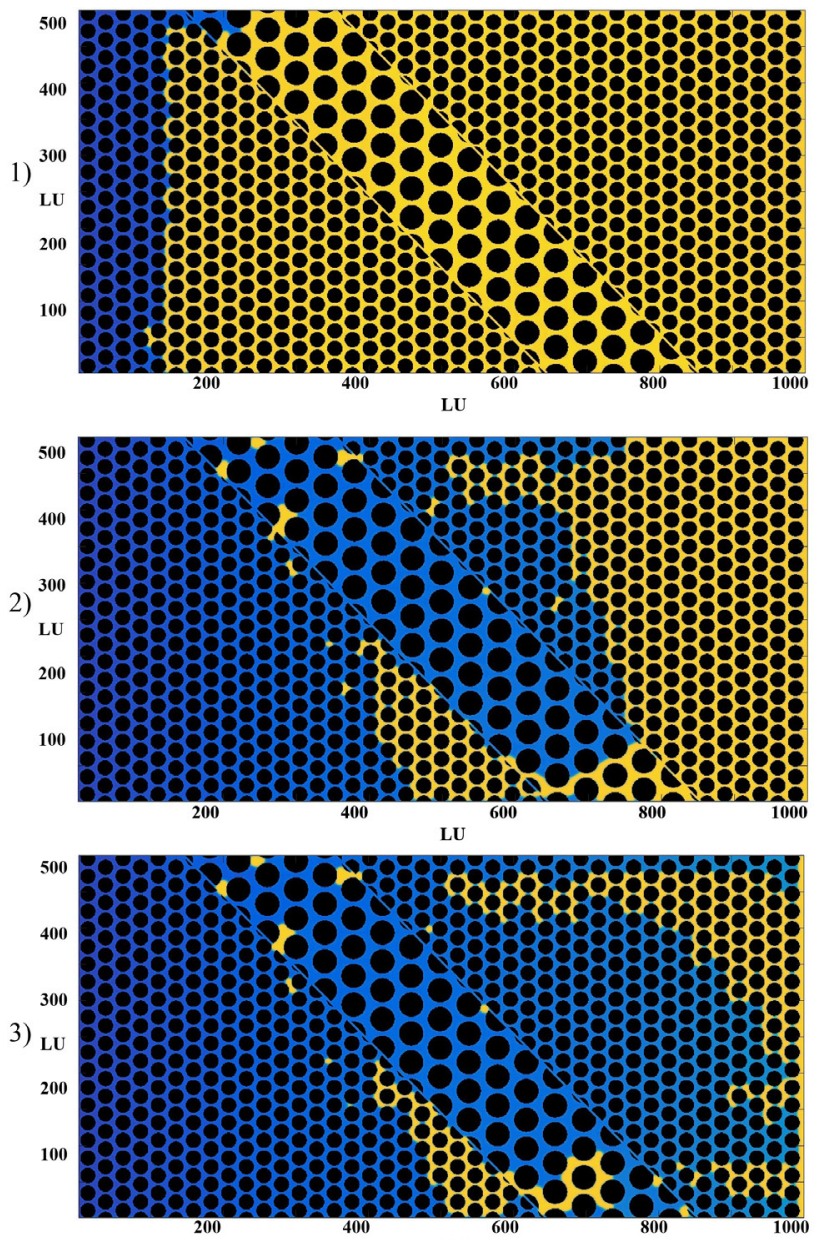

(a)
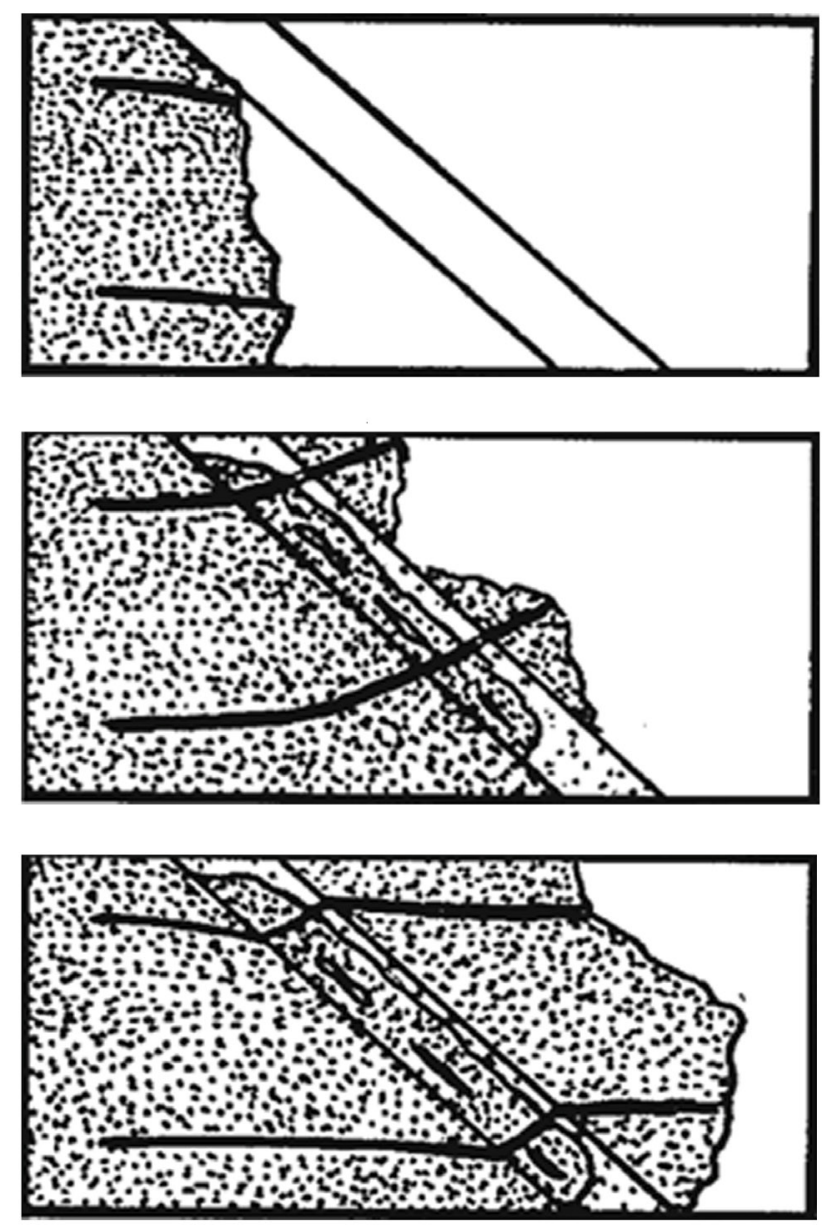

(b)

Figure 7: (a) LBM simulation and (b) experimental glass-bead pack (Dawe et al., 2o11) water flooding in high-permeable fault structure 1) initial stage 2) intermediate stage 3) breakthrough time.

the units of the all variables to the lattice units, the simulations were performed with a discharge of $60(\mathrm{ml} / \mathrm{h})$. The relaxation times of 0.875 and 0.5555 and the densities of 0.875 and 1 were set for the displaced fluid (oil) and the displacing fluid (water), respectively.

\subsubsection{High Permeability Stripe}

The results of water flooding in a high permeable fault zone are shown in Figure 7. During water flooding in a high permeability stripe in the early stage, water penetrates through the low permeability layer by a stable front. When the fluid front reaches the boundary between the low and high permeable layer, if displacing fluid pressure exceeds the capillary pressure between two layers, it enters the high permeable layer. So after filling layer 1, it passes through the shortest path of layer 2 with an angle of around 90 degrees. In the low permeable layer, oil is efficiently swept, while in the high permeable layer, oil is bypassed. W In a high permeable fault zone, water flooding obeys Hubbert's law (see Figure 5). Also, fluid front and flow pathway of LBM simulation were comparable with the experimental results of the previous study on a glass bead micromodel (Dawe et al., 2011).

\subsubsection{Low Permeability Stripe}

The results of water flooding in a low permeable fault zone are shown in Figure 8. During water flooding in a low permeability stripe, water penetrates the high permeable layer with an unstable front. After reaching the low permeable layer (Layer 2), water completely sweeps the oil in this stripe. After filling this layer, water will bypass the next high permeable layer in the shortest pathway at 90 degrees. In a low permeable fault zone, water flooding obeys Hubbert's law (see Figure 5). Also, fluid front and flow pathway of LBM simulation were comparable with the experimental results of the previous study on a glass bead micromodel (Dawe et al., 2011).

As can be seen in Figure 7 and Figure 8, flow direction in the boundaries of domains, change the fluid pathway and they obey Hubbert's law. These phenomenon are obvious in the experimental glass-bead pack results of Dawe et al. in 2011, as shown in Figure 7(b) and Figure 8(b) (Dawe et al., 2011). 

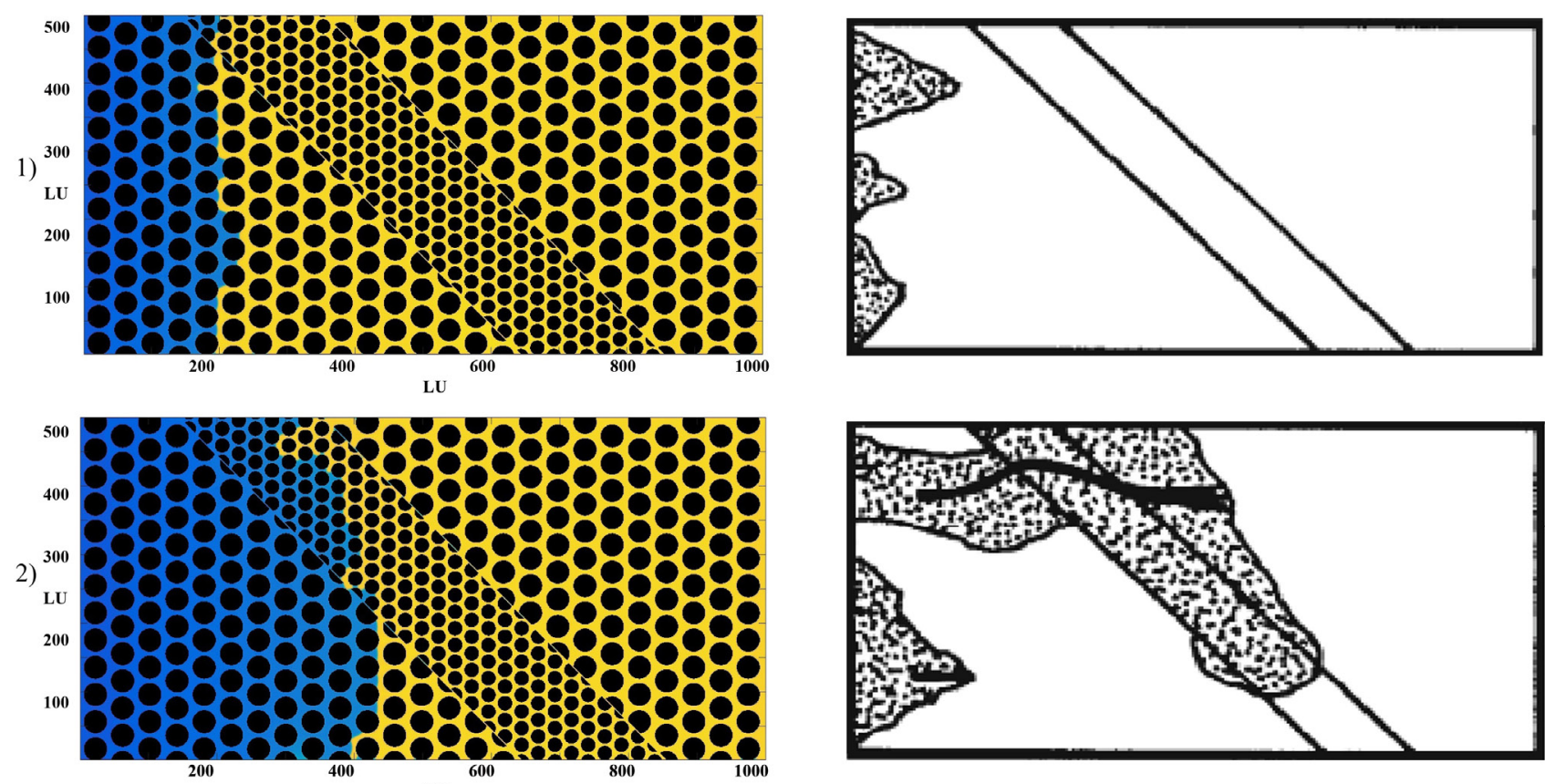

LU
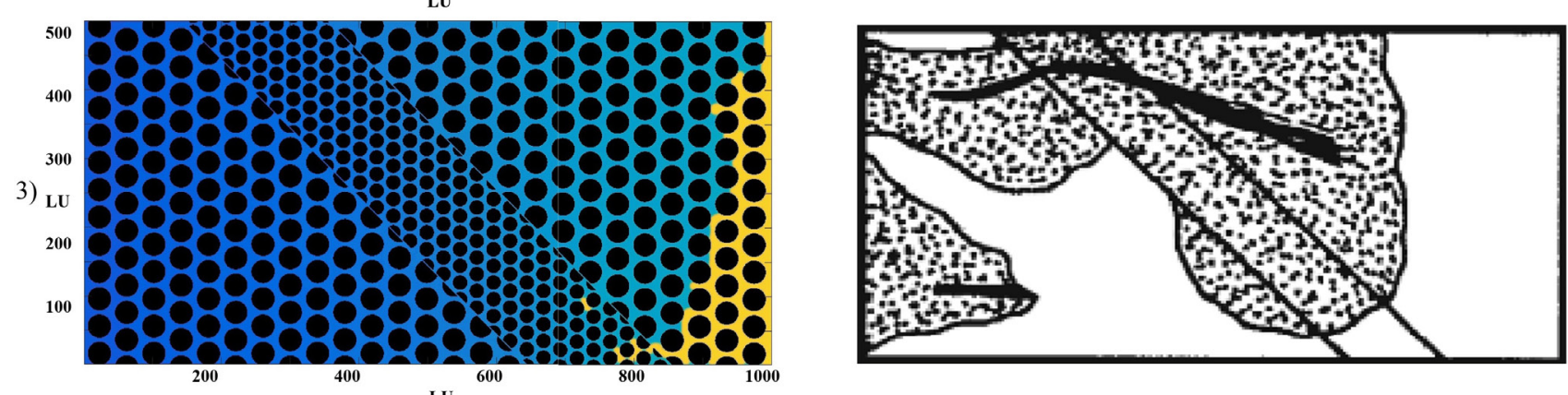

(a)

(b)

Figure 8: (a) LBM simulation and (b) experimental glass-bead pack (Dawe et al., 2o11) water flooding in low-permeable fault structure 1) initial stage 2) intermediate stage 3) breakthrough time.

\subsection{Water Flooding in a Discontinuity}

A fracture or discontinuity between two porous media consisting of two homogeneous layers with very low and high permeabilities is a hot topic for considering the effect of heterogeneity (Conn et al., 2014; Dong et al., 2017; Xiao et al., 2018). The following paragraphs are experimental and numerical evaluation of immiscible water flooding for sweep efficiency and streamlines tracking purposes in a fracture or discontinuity between two porous media.

Experimentally, a heterogeneous porous medium was fabricated using the method presented in the glass micromodel fabrication section. The experimental setup is shown in Figure 1. The glass micromodel had 1 inlet port and 1 outlet port at the centre of the model with 1.06 $\mathrm{mm}$ width. The porous medium had dimensions of 3.987 $\times 1.8 \mathrm{~cm}$ and the pore space height was $50 \mu \mathrm{m}$. The first layer has small pillars with a diameter of $450 \mu \mathrm{m}$, pore throat size of $120 \mu \mathrm{m}$, and $75 \%$ porosity. The second layer had large pillars with a diameter of $1350 \mu \mathrm{m}$, pore throats size of $360 \mu \mathrm{m}$, and $49 \%$ porosity. The size of the discontinuity or crack between two layers was $900 \mu \mathrm{m}$. The distances between the grains and walls was equal to pore throat sizes. The size of all inlet and outlet channels were $1200 \mu \mathrm{m}$. Arvandan crude oil from the south of Iran with a density of $0.875\left(\mathrm{gr} / \mathrm{cm}^{3}\right)$ at $25^{\circ} \mathrm{C}$, a dynamic viscosity of $5(\mathrm{mPa} \mathrm{s})$ at $25^{\circ} \mathrm{C}$, and total acid number of $0.12(\mathrm{mg} \mathrm{KOH} / \mathrm{g})$ was used for saturation of porous medium, and distilled water was used as the displacing fluid. Before starting the experiment, the glass micromodel was washed with deionized water and toluene. Then, it was dried by air blowing and exposing it to a high temperature. After that, the micromodel was completely saturated with the oil. Finally, distilled water was pumped into the micromodel at a constant flow rate.

The results of the experiment by discharges of 1 and $200(\mathrm{ml} / \mathrm{h})$ with equivalent capillary numbers of 0.07 and 14 are shown in Figure 9. In a low discharge of 1 $(\mathrm{ml} / \mathrm{h})$, the tendency of the fluid to pass through the pores is more than a higher discharge of $200(\mathrm{ml} / \mathrm{h})$. The crack or discontinuity between the two layers plays the 
a)
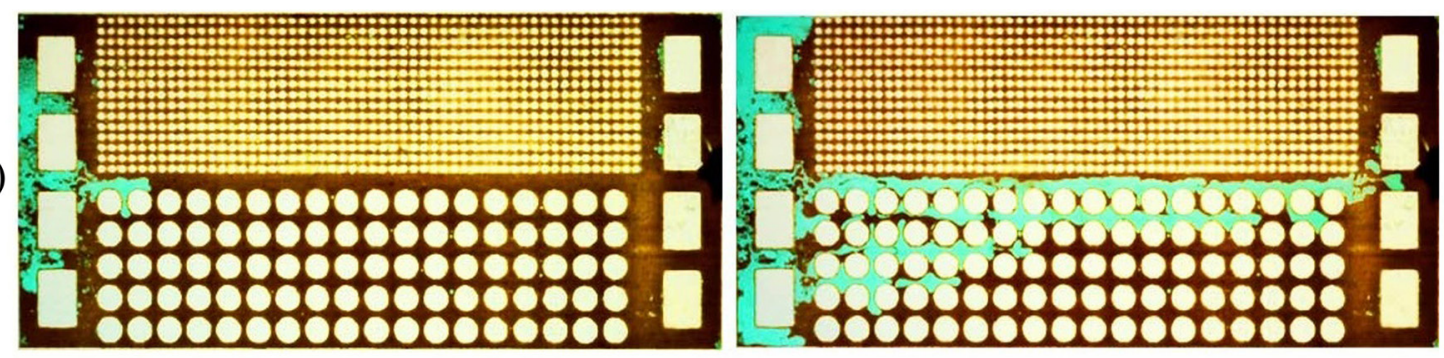

b)

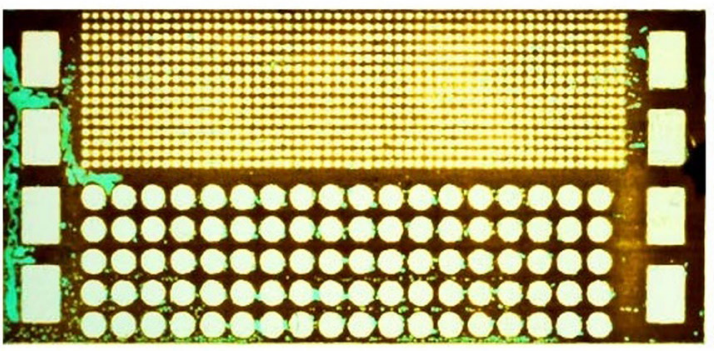

(1)

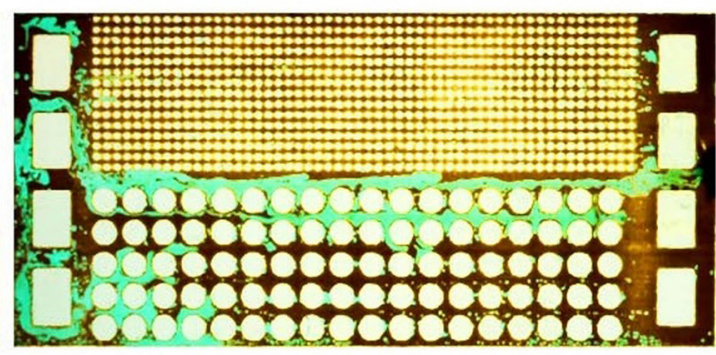

(2)

Figure 9: Experimental water flooding by the flow rate of $Q=1(a), Q=200(6)$ in the glass micromodel in the initial time step (1) and breakthrough time step (2) in the heterogeneous porous medium saturated with Arvandan oil.

a)

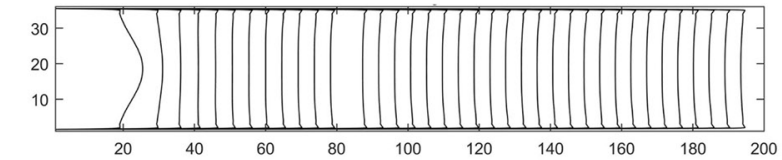

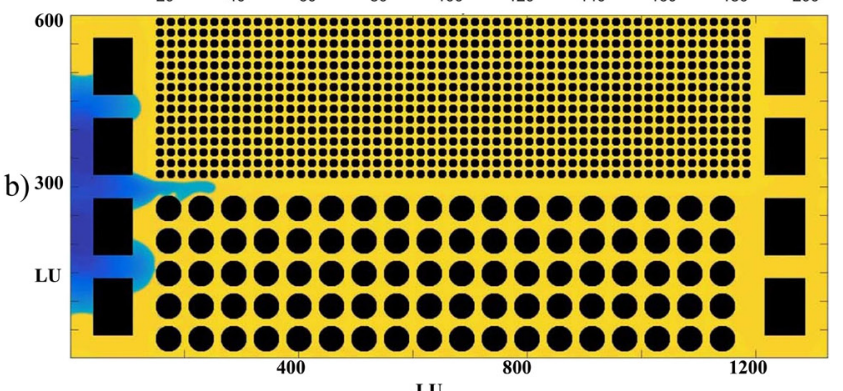

c)
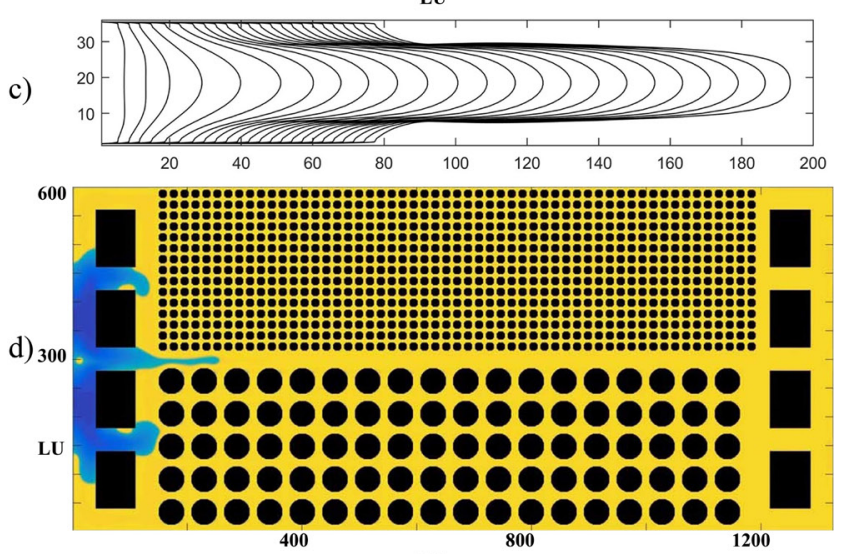

(1)
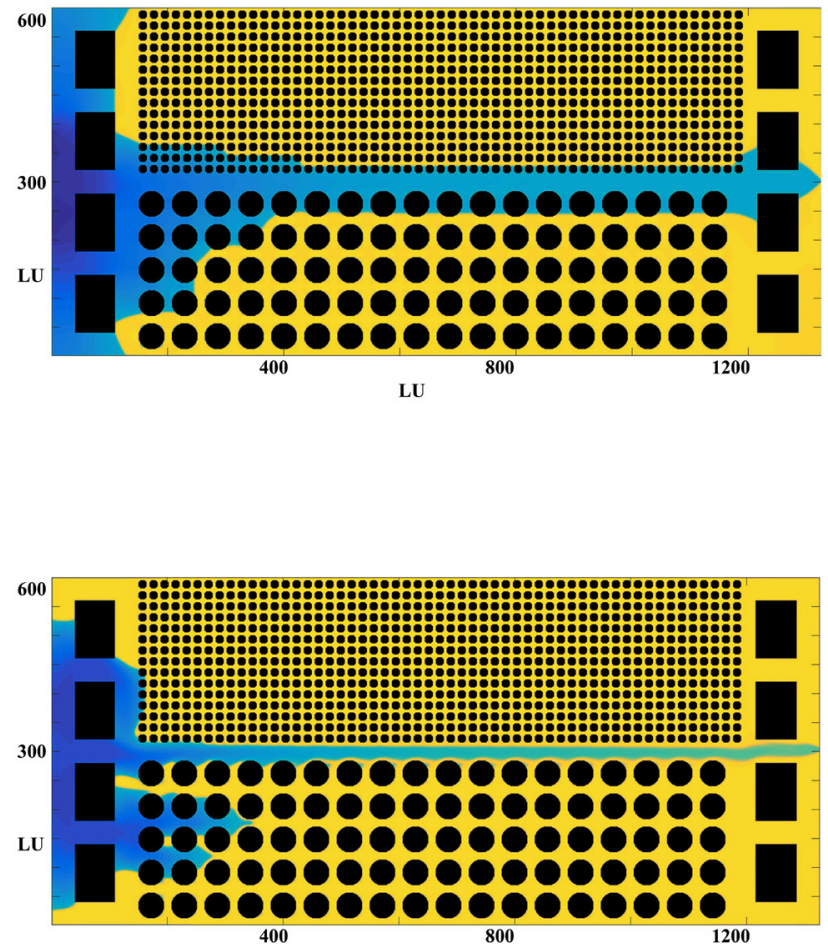

(2)

Figure 10: Simulation of water flooding in Arvandan oil by flow rates of $Q=1(b), Q=200(d)$ in the heterogeneous porous medium with permeability contrast in the initial time step (1) and breakthrough time step (2) and in a microchannel (a,c) by flow rate of $Q=1(a), Q=200(c)$ in different time steps.

main role in the flow discharge through the porous medium. Fluids' tendency to pass through the fine and coarse layers decreases as the flow rate increases. An in- crease in flow rate from 1 and $200(\mathrm{ml} / \mathrm{h})$ causes a reduction in sweep efficiency from $14 \%$ to $7.3 \%$ by the moment of breakthrough, respectively (see Figure 11). 


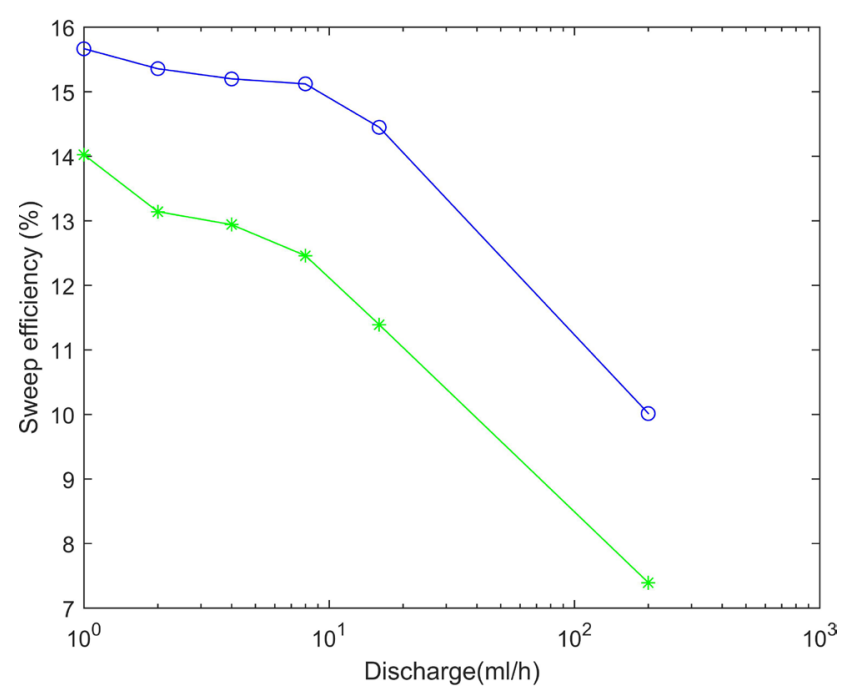

Figure 11: Sweep efficiency in different flow rate for LBM simulation (blue line, o mark) and glass micromodel (green line, * mark)

Fluids and boundary conditions in the simulation were similar to the experiment. Zou-He velocity boundary scheme is used at both inlet and outlet of the porous medium (Zou and He, 1997) and, the half-way bounceback boundary condition is used for solid surfaces. After converting the flow units from SI to the lattice unit, the numerical method ran with discharges of 1 and 200 $(\mathrm{ml} / \mathrm{h})$ were equivalent to the capillary numbers of 0.07 and 14. The relaxation times of 0.875 and 0.5555 and the densities of 0.875 and 1 were set for the displaced fluid (oil) and displacing fluid (water), respectively. The results (see Figure 10) show fluid movement is in piston form in a very low capillary number. As a result, the increase in flow rate caused the fluid front piston pattern to change to the fingering form. Simultaneously, the crack has the main role in the fluid flow pathway in the heterogeneous porous medium. An increase in flow rate from 1 and $200(\mathrm{ml} / \mathrm{h})$ caused a reduction in the sweep efficiency from $15.6 \%$ to $10 \%$ at the moment of breakthrough, respectively (see Figure 11).

The results of the experimental and numerical method were consistent with hydrodynamic concepts. Sweep efficiency in both the micromodel water flooding and the LBM simulation were decreasing. The sweep efficiency curves of them versus flow rate were similar with a shift of about 2 percent (see Figure 11). So, a pseudo-potential model, which is used in this study, can efficiently track fluid front in a pore-scale in different heterogeneous systems. Also, an experimental glass micromodel is a sufficient, precise, cheap, and priceless tool for visualization of the fluid front compared to other experimental methods.

\section{Conclusions}

In this current study, the effects of capillary number on viscous fingering pattern in porous media with heterogeneity in permeability, such as a fault zone, and a discontinuity were studied. In the fault, the results showed that when the permeability of the fault zone is less or more than the vicinity layer, sweep efficiency, and fingering pattern of the fault zone and adjacent layer were different. In addition, based on Hubbert's law, the streaming direction depends on heterogeneity and deep angle.

In the discontinuity, the results showed that a crack between the two porous medium significantly contributed to the fluid flow, and the sweep efficiency decreases as the flow rate increases. The LBM and glass micromodel results showed acceptable consistencies with the physics of fluid flow. They showed that a pseudo-potential model has a good ability and accuracy in the simulation of immiscible multi-component fluid displacement. Also, a glass micromodel is an efficient tool to fabricate any structure and pattern of heterogeneous porous media, and visualize fluid flow. It is recommended that more glass micromodels with heterogeneity in both permeability and wettability should be studied in future works, and also, LBM simulation is enhanced for solving real-life problems.

\section{References}

Andrew, M., Bijeljic, B., Blunt, M.(2014): Reservoir condition pore scale imaging of the capillary trapping of $\mathrm{CO} 2$. Energy Procedia, 63, 5427-5434. doi: 10.1016/j.egypro.2014.11.573

Andrew, M., Menke, H., Blunt, M. J., Bijeljic, B.(2015): The Imaging of Dynamic Multiphase Fluid Flow Using Synchrotron-Based X-ray Microtomography at Reservoir Conditions. Transport in Porous Media, 110(1), 1-24. doi: 10.1007/s11242-015-0553-2

Bear, J.(2013): Dynamics of fluids in porous media. Courier Corporation, New York, 757 p. doi: 10.1097/00010694197508000-00022

Berg, R.(1970): Method for Determining Permeability from Reservoir Rock Properties. Transactions - Gulf Coast Association of Geological Societies, 20, 303-335.

Bjoerlykke, K.(1989): Sedimentology and petroleum geology. New York, NY (US); Springer-Verlag, 363 p.

Blunt, M. J., Bijeljic, B., Dong, H., Gharbi, O., Iglauer, S., Mostaghimi, P., Paluszny, A., Pentland, C.(2013): Porescale imaging and modelling. Advances in Water Resources, 51, 197-216. doi: 10.1016/j.advwatres.2012.03.003

Caruana, A., Dawe, R. A.(1996): Flow behaviour in the presence of wettability heterogeneities. Transport in Porous Media, 25(2), 217-233. doi: 10.1007/BF00135857

Chaudhari, L., Hadia, N. J., Mitra, S. K., Vinjamur, M.(2011): Flow visualization of two-phase flow through layered porous media. Energy Sources, Part A: Recovery, Utilization and Environmental Effects, 33(10), 948-958. doi: 10.1080/ 15567030903330702

Chen, S., Doolen, G. D.(1998): Lattice boltzmann method for fluid flows. Annual Review of Fluid Mechanics, 30(1), 329-364. doi: 10.1146/annurev.fluid.30.1.329

Conn, C. A., Ma, K., Hirasaki, G. J., Biswal, S. L.(2014): Visualizing oil displacement with foam in a microfluidic device with permeability contrast. Lab on a Chip, 14(20), 3968-3977. doi: 10.1039/c4lc00620h 
Crandall, D., Ahmadi, G., Leonard, D., Ferer, M., Smith, D. H.(2008): A new stereolithography experimental porous flow device. Review of Scientific Instruments, 79(4), 044501. doi: 10.1063/1.2903740

Dawe, R. A., Caruana, A., Grattoni, C. A.(2011): Immiscible Displacement in Cross-Bedded Heterogeneous Porous Media. Transport in Porous Media, 87(1), 335-353. doi: 10.1007/s11242-010-9687-4

Dawe, R. A., Wheat, M. R., Bidner, M. S.(1992): Experimental investigation of capillary pressure effects on immiscible displacement in lensed and layered porous media. Transport in Porous Media, 7(1), 83-101. doi: 10.1007/ BF00617318

Dawe, R. A., Caruana, A., Grattoni, C. A.(2010): Microscale Visual Study of End Effects at Permeability Discontinuities. Transport in Porous Media, 86(2), 601-616. doi: 10.1007/s11242-010-9642-4

Dong, B., Yan, Y. Y., Li, W. Z.(2011): LBM Simulation of Viscous Fingering Phenomenon in Immiscible Displacement of Two Fluids in Porous Media. Transport in Porous Media, 88(2), 293-314. doi: 10.1007/s11242-011-9740-y

Dong, P., Puerto, M., Ma, K., Mateen, K., Ren, G., Bourdarot, G., Morel, D., Bourrel, M., Biswal, S. L., Hirasaki, G. (2017): Low-interfacial-tension foaming system for enhanced oil recovery in highly heterogeneous/fractured carbonate reservoirs. Proceedings - SPE International Symposium on Oilfield Chemistry, April(1), 410-429. doi: 10.2118/184569-ms

Ferer, M., Ji, C., Bromhal, G. S., Cook, J., Ahmadi, G., Smith, D. H.(2004): Crossover from capillary fingering to viscous fingering for immiscible unstable flow: Experiment and modeling. Physical Review E - Statistical Physics, Plasmas, Fluids, and Related Interdisciplinary Topics, 70(1), 016303. doi: 10.1103/PhysRevE.70.016303

Gonnella, G., Lamura, A., Sofonea, V.(2007): Lattice Boltzmann simulation of thermal nonideal fluids. Physical Review E - Statistical, Nonlinear, and Soft Matter Physics, 76(3), 36703. doi: 10.1103/PhysRevE.76.036703

Gunstensen, A. K., Rothman, D. H., Zaleski, S., Zanetti, G.(1991): Lattice Boltzmann model of immiscible fluids. Physical Review A, 43(8), 4320-4327. doi: 10.1103/PhysRevA.43.4320

He, X., Luo, L.(1997): Theory of the lattice Boltzmann method: From the Boltzmann equation to the lattice Boltzmann equation. Physical Review E, 56(6), 6811-6817. doi: 10.1103/PhysRevE.56.6811

He, X., Shan, X., Doolen, G. D.(1998): Discrete Boltzmann equation model for nonideal gases. Physical Review E Statistical Physics, Plasmas, Fluids, and Related Interdisciplinary Topics, 57(1), 13-16. doi: 10.1103/PhysRevE.57.R13

Holtzman, R.(2016): Effects of Pore-Scale Disorder on Fluid Displacement in Partially-Wettable Porous Media. Scientific Reports, 6(October), 1-10. doi: 10.1038/srep36221

Homsy, G.(1987): Viscous Fingering In Porous Media. Annual Review of Fluid Mechanics, 19(1), 271-311. doi: 10.1146/ annurev.fluid.19.1.271

Huang, H., Sukop, M. C., Lu, X. Y.(2015): Multiphase Lattice Boltzmann Methods: Theory and Application. John Wiley \& Sons, 1-373 p. doi: 10.1002/9781118971451
Huang, Y., Ringrose, P. S., Sorbie, K. S.(1995): Capillary Trapping Mechanisms in Water-Wet Laminated Rocks. SPE Reservoir Engineering, 10(4), 287-292. doi: 10.2118/ 28942-PA

Hubbert, M. K.(1940): The theory of ground-water motion. The Journal of Geology, 48(8), 785-944.

Kortekaas, T.(1985): Water/oil displacement characteristics in crossbedded reservoir zones. Society of Petroleum Engineers Journal, 25, 917-926. doi: 10.2118/12112-PA

Lenormand, R., Touboul, E., Zarcone, C.(1988): Numerical models and experiments on immiscible displacements in porous media. Journal of Fluid Mechanics, 189(1), 165187. doi: 10.1017/S0022112088000953

Liu, H., Zhang, Y., Valocchi, A. J.(2015): Lattice boltzmann simulation of immiscible fluid displacement in porous media: Homogeneous versus heterogeneous pore network. Physics of Fluids, 27(5), 052103. doi: 10.1063/1.4921611

McKean, H. C., Dawe, R. A.(1990): Numerical Simulation Of Displacements In Systems Containing A Lens Heterogeneity. Journal of Canadian Petroleum Technology, 29(06). doi: 10.2118/90-06-10

Menke, H., Bijeljic, B., Andrew, M., Blunt, M. J.(2014): Dynamic Pore-scale Imaging of Reactive Transport in Heterogeneous Carbonates at Reservoir Conditions. Energy Procedia, 63, 5503-5511. doi: 10.1016/j.egypro.2014.11.583

Mohamad, A. A.(2011): Lattice Boltzmann Method, Fundamentals and Engineering Applications with Computer Codes. Springer, London, 195 p.

Mohammadi, S., Maghzi, a., Ghazanfari, M. H., Masihi, M., Mohebbi, a., Kharrat, R.(2013): On the Control of Glass Micro-model Characteristics Developed by Laser Technology. Energy Sources, Part A: Recovery, Utilization, and Environmental Effects, 35(3), 193-201. doi: 10.1080/ 15567036.2010.516325

Muljadi, B. P., Blunt, M. J., Raeini, A. Q., Bijeljic, B.(2016): The impact of porous media heterogeneity on non-Darcy flow behaviour from pore-scale simulation. Advances in Water Resources, 95, 329-340. doi: 10.1016/j.advwatres.2015.05.019

Nabovati, A.(2009): Pore level simulation of single and two phase flow in porous media using lattice Boltzmann method. University of New Brunswick (Canada), 190 p.

Piller, M., Casagrande, D., Schena, G., Santini, M.(2014): Pore-scale simulation of laminar flow through porous media. Journal of Physics: Conference Series, 501(1), 12010. doi: 10.1088/1742-6596/501/1/012010

Ringrose, P. S., Sorbie, K. S., Corbett, P. W. M., Jensen, J. L. (1993): Immiscible flow behaviour in laminated and crossbedded sandstones. Journal of Petroleum Science and Engineering, 9(2), 103-124. doi: 10.1016/0920-4105(93) 90071-L

Roti, Ø., Dawe, R. A.(1993): Modelling fluid flow in crossbedded sections. Transport in Porous Media, 12(2), 143159. doi: 10.1007/BF00616977

Safari, M., Ameri, M. J., Naderifar, A.(2018): Adaptive control design for a nonlinear parabolic PDE: Application to water coning. Canadian Journal of Chemical Engineering, 96(9), 1926-1936. doi: 10.1002/cjce.23174 
Safari, M., Ameri, M. J., Naderifar, A.(2019): An efficient boundary control for porous media equation: Motivated by water coning problem. Canadian Journal of Chemical Engineering, 97(4), 888-902. doi: 10.1002/cjce.23323

Safari, M., Ameri, M. J.(2019): Reservoir Control and Identification: Motivated by Water Coning. IOP Conference Series: Materials Science and Engineering, 495(1), 12079. doi: 10.1088/1757-899X/495/1/012079

Safari, M., Ameri, M. J.(2019): Adaptive Control design for a $3 \mathrm{D}$ reservoir model under water coning. IOP Conference Series: Materials Science and Engineering, 495(1), 12078. doi: 10.1088/1757-899X/495/1/012078

Sbragaglia, M., Benzi, R., Biferale, L., Succi, S., Sugiyama, K., Toschi, F.(2007): Generalized lattice Boltzmann method with multirange pseudopotential. Physical Review E Statistical, Nonlinear, and Soft Matter Physics, 75(2), 026702. doi: 10.1103/PhysRevE.75.026702

Shabro, V., Prodanovic, M., Arns, C.(2010): Pore-scale modeling of two-phase flow. InXVIII International Conference on Computational Methods in Water Resources, 11-15.

Shan, X., Chen, H.(1993): Lattice Boltzmann model for simulating flows with multiple phases and components. Physical Review E, 47(3), 1815-1819. doi: 10.1103/PhysRevE.47.1815

Shiri, Y., Hassani, H., Nazari, M., Sharifi, M.(2018): The effects of grain geometry on waterflooding and viscous fingering in micro-fractures and porous media from a lattice
Boltzmann method study. Molecular Simulation, 44(9), 708-721. doi: 10.1080/08927022.2018.1439585

Silva, M. De, Dawe, R. A.(2003): Effects of Permeability and Wettability Heterogeneities on Flow in Porous Media. 987-1003. doi: 10.2523/81164-ms

Weber, K. J.(1982): Influence of Common Sedimentary Structures on Fluid Flow in Reservoir Models. Journal of Petroleum Technology, 34(03), 665-672. doi: 10.2118/9247-PA

Xiao, S., Zeng, Y., Vavra, E. D., He, P., Puerto, M., Hirasaki, G. J., Biswal, S. L.(2018): Destabilization, Propagation, and Generation of Surfactant-Stabilized Foam during Crude Oil Displacement in Heterogeneous Model Porous Media. Langmuir, 34(3), 739-749. doi: 10.1021/acs. langmuir.7b02766

Zerai, B., Saylor, B. Z., Kadambi, J. R., Oliver, M. J., Mazaheri, A. R., Ahmadi, G., Bromhal, G. S., Smith, D. H. (2005): Flow characterization through a network cell using particle image velocimetry. Transport in Porous Media, 60(2), 159-181. doi: 10.1007/s11242-004-4796-6

Zhang, C., Oostrom, M., Wietsma, T. W., Grate, J. W., Warner, M. G.(2011): Influence of viscous and capillary forces on immiscible fluid displacement: Pore-scale experimental study in a water-wet micromodel demonstrating viscous and capillary fingering. Energy and Fuels, 25(8), 3493 3505. doi: 10.1021/ef101732k

Zou, Q., He, X.(1997): On pressure and velocity boundary conditions for the lattice Boltzmann BGK model. Physics of Fluids, 9(6), 1591-1596. doi: 10.1063/1.869307

\section{SAŽETAK}

\section{Praćenje kretanja granice dvaju fluida u zoni rasjeda i diskontinuiteta s heterogenom propusnošću}

Praćenje kretanja granice dvaju fluida vrlo je važno kod protjecanja dviju faza u poroznoj heterogenoj sredini, osobito kod primjene metoda povećanja iscrpka nafte. S obzirom na viskoznost fluida i kapilarni broj moguća su tri različita oblika toka: stabilni te viskozno i kapilarno probijanje. Dodatno, granica fluida i koeficijent obuhvata ležišta istiskivanjem ovise i o heterogenosti porozne sredine. U ovome istraživanju heterogena porozna sredina predstavljena je (1) zonom normalnoga rasjeda ili unakrsne slojevitosti s heterogenom propusnošću i (2) frakturom ili diskontinuitetom između dviju poroznih sredina koja se sastoji od dvaju homogenih slojeva s vrlo niskom i vrlo visokom propusnošću, u kojoj je izvedeno nemješljivo zavodnjavanje kako bi se promatrao koeficijent obuhvata ležišta istiskivanjem i pratilo strujnice toka fluida. Razmatranjem eksperimentalnoga staklenog mikromodela i rezultata simulacije diskontinuiteta utvrđeno je da glavni tok fluida prati pukotinu. Nakon proboja fluid nastoji prodrijeti i kroz međuprostor sačinjen od finih i grubih čestica uokolo pukotine. Štoviše, povećanjem protoka s 1 na $200 \mathrm{ml} / \mathrm{h}$, i kod eksperimentalnoga i kod simulacijskoga modela, došlo je do smanjenja koeficijenta obuhvata ležišta istiskivanjem do trenutka proboja s $14 \%$ na 7,3\% odnosno s 15,6 \% na $10 \%$. U zoni rasjeda uočena je ovisnost koeficijenta obuhvata ležišta istiskivanjem i strujnica utisnutoga fluida o upadnome kutu na površinu rasjeda i propusnosti slojeva. Prezentirani stakleni mikromodel i rešetkasti Boltzmannov model bili su u skladu s dinamikom fluida i oba se mogu koristiti za preciznu ocjenu koeficijenta obuhvata ležišta istiskivanjem i vizualizaciju preferiranoga puta kretanja fluida kroz područja unakrsne slojevitosti ili diskontinuiteta kod metoda povećanja iscrpka nafte.

\section{Ključne riječi:}

diskontinuitet, rasjed, rešetkasta Boltzmannova metoda, granica fluida, strujnice

\section{Author's contribution}

Yousef Shiri (assistant professor, Ph.D., Petroleum Engineering) provided the numerical code and the analysis. Hossein Hassani (associated professor, Ph.D., Petroleum Engineering) provided the interpretations and presentation of the results. 